\title{
Empresa Doente, Funcionário Estressado: analisando a saúde organizacional como influenciadora do stress no trabalho
}

\author{
Monize Sâmara Visentini ${ }^{1}$ \\ Eliete dos Reis ${ }^{2}$ \\ Nilson Amaury Siqueira ${ }^{3}$ \\ Kelmara Mendes Vieira 4 \\ Claudia Medianeira Cruz Rodrigues ${ }^{5}$
}

\section{Resumo}

Este trabalho investigou a influência da percepção de saúde organizacional sobre o stress no trabalho dos funcionários de restaurantes da cidade de Santa Maria RS. Para tanto, utilizou-se uma survey com os funcionários de sete restaurantes, três públicos e quatro privados. Realizou-se uma análise fatorial que apresentou cinco fatores para stress no trabalho e quatro fatores de saúde organizacional. Através de uma análise de correlação, confirmou-se a multidimensionalidade desses construtos. Dados esses resultados, para verificar a influência da percepção de saúde organizacional sobre o stress ocupacional, realizou-se uma análise de regressão e foram encontrados cinco modelos válidos que atendem aos pressupostos necessários. Entretanto, esses modelos tiveram baixo poder de explicação, indicando que os fatores de stress ocupacional não são suficientes para explicar a saúde organizacional, devendo ser investigados outros aspectos relativos ao ambiente laboral que interferem na percepção de stress no trabalho.

Palavras-chave: Stress no Trabalho. Saúde Organizacional. Funcionários de restaurantes.

\footnotetext{
1Mestre em Administração e Doutoranda em Administração do Programa de Pós-Graduação em Administração da Universidade Federal do Rio Grande doSul. Endereço: Estrada RS 509, 7260 (LOJA), Bairro Camobi, CEP: 97.110-620-Santa Maria, RS.E-mail:monize.s.visentini@gmail.com. ${ }^{2}$ Mestranda do Programa de Pós-graduação em Administração da Universidade Federal de Santa Maria. Rua Floriano Peixoto, 1184 - Sala 500 -CEP: 97.015-372 -Santa Maria, RS-Brasil.E-mail: elietedosreis@yahoo.com.br.

${ }^{3}$ Mestrando do Programa de Pós-graduação em Administração da Universidade Federal de Santa Maria. Rua Floriano Peixoto, 1184 -Sala 500 -CEP: 97.015-372 -Santa Maria, RS - Brasil.E-mail: nilsonamaury@hotmail.com.

${ }^{4}$ Doutora em Administração pela Universidade Federal do Rio Grande do Sul e Professora Adjunta do Departamento de Ciências Administrativas da Universidade Federal de Santa Maria. Endereço: Rua Floriano Peixoto, 1184 - Sala 500 - CEP: 97015-372 - Santa Maria, RS - Brasil. Email:kelmara@smail.ufsm.br.

${ }^{5}$ Doutora em Engenharia de Produção pela Universidade Federal do Rio Grande do Sul e Professora Adjunta do Departamento de Engenharia de Produção e Transportes da Universidade Federal do Rio Grande do Sul. Endereço: Rua Oswaldo Aranha, 99, 5 andar, Sala LOPP, Centro, CEP: 90.035-190, Porto Alegre, RS - Brasil.E-mail: claudia.rodrigues@sai.ufrgs.br.
} 


\section{Introdução}

O mundo do trabalho está passando por uma sequência de transformações que se refletem na saúde das organizações e, diretamente, no indivíduo que dela faz parte. $\mathrm{O}$ avanço da tecnologia, ao invés de proporcionar ao indivíduo menos atividades laborais e maior otimização do tempo, tem gerado sobrecarga de informações e acelerado o ritmo do trabalho. Dessa forma, segundo Cooper, citado por Rossi, Perrewé e Sauter (2007), à medida que um número maior de empresas adota uma perspectiva globalizada, tanto elas quanto os indivíduos por elas empregados constatam que o sucesso em nível global exige mudanças fundamentais em suas estruturas corporativas, bem como nas competências individuais. Esses acontecimentos podem estar refletindo na qualidade de vida dos indivíduos, a qual pode ser influenciada pela saúde organizacional e, consequentemente, pelo stress no trabalho.

Nesse contexto, Cox e Howarth (1990) definem como organização saudável aquela que não contribui para o desencadeamento do stress nos empregados. Assim, a importância dessa conceituação confirma-se pela busca contínua do que proporciona bem-estar e satisfação ao indivíduo no seu ambiente de trabalho. Complementarmente, Dejoy e Wilson (2003) consideram, como premissa-chave da saúde organizacional, a maximização do capital humano pela otimização da qualidade de vida no trabalho, afirmando que a promoção de saúde ocupacional deve identificar e gerenciar os fatores de riscos dos indivíduos, ocasionados por estressores como a carga de trabalho, conflito e ambiguidade de papéis, controle e autonomia.

Nesse sentido, importantes pesquisas e estudos sobre esse tema têm emergido na literatura devido ao impacto negativo que o stress ocupacional causa à saúde e ao bem-estar do empregado e, consequentemente, no funcionamento e na efetividade das organizações (PASCHOAL; TAMAYO 2004). Esses autores citam, a fim de reforçar o seu posicionamento, a abordagem teórica de Lazarus (1995), segundo a qual o stress ocupacional é um processo que implica uma transação entre o empregado e o seu ambiente de trabalho. Nota-se, assim, que se o indivíduo não pertence a uma organização saudável terá grandes chances de sofrer de stress, oriundo do ambiente laboral. Assim, Tamayo (2007, p. 26) destaca que "desajustes entre o ambiente de trabalho e as motivações, interesses e outras características do trabalhador são a principal fonte de stress". Ainda, trabalhadores estressados 
diminuem seu desempenho e acrescem os custos das organizações com problemas de saúde, aumento do absenteísmo, da rotatividade e de acidentes no local de trabalho (PASCHOAL; TAMAYO, 2004).

Assim, observa-se que as rotinas diárias do ambiente laboral, a estrutura e o funcionamento das empresas moldam e definem a saúde organizacional, e, se não forem bem administradas, podem gerar desgaste entre os indivíduos, causando transtornos e stress ocupacional. Assim, para Quick et al. (2007), proporcionar ambientes saudáveis ao trabalhador, torna-se imprescindível visto que, através da prevenção, pode-se impedir que níveis de stress cheguem a um ponto em que ocorram resultados negativos para a saúde e o bem-estar do indivíduo. Ainda, se as condições de trabalho forem caracterizadas por atributos negativos como falta de objetivo e sentido à vida, falta de apoio social $e$ insuficiência de recompensas materiais, elas, pelo menos, a longo prazo, poderão causar e acelerar o curso ou desencadear os sintomas de problemas de saúde do indivíduo e, consequentemente, de stress ocupacional (LEVI, 2000).

Essas questões, referentes à saúde organizacional e ao stress ocupacional, indicam que a investigação desse assunto é bastante relevante para o meio empresarial e acadêmico, pois afetam consideravelmente o desempenho profissional e o resultado da organização em geral. Salienta-se que, quando o indivíduo está submetido a um constante esforço físico e uma sobrecarga de trabalho e tensões do ambiente laboral, como no caso dos funcionários de restaurantes, as investigações, relacionando stress ocupacional e saúde organizacional, tornam-se ainda mais significativas. Sendo assim, este trabalho objetiva (I) investigar a influência da Percepção de Saúde Organizacional sobre o stress no Trabalho dos funcionários de restaurantes da cidade de Santa Maria - RS. Além disso, ainda se busca (II) verificar se há diferença entre os fatores de percepção de saúde organizacional $e$ os estressores do trabalho que afetam os funcionários dos restaurantes públicos e privados; $e$ (III) identificar a relação entre a percepção dos fatores de stress ocupacional e de saúde organizacional.

\section{Discussões sobre a Saúde Organizacional}

O interesse pela investigação dos fatores que proporcionam um ambiente saudável nas organizações tem sido crescente no meio científico. Segundo Hernandez (2007), pesquisadores e profissionais da área de comportamento 
organizacional têm estudado o que proporciona bem-estar ao indivíduo no ambiente de trabalho. Isso se deve ao fato de que o contexto organizacional mudou nas últimas décadas, ou seja, o profissional espera receber da organização mais do que recompensas pelo trabalho realizado, ele busca sentir-se reconhecido e satisfeito, além de encontrar um ambiente de trabalho saudável que possibilite crescimento pessoal e profissional (HERNANDEZ, 2007). Dessa maneira, as organizações devem entender que sua estrutura e funcionamento podem ter um grande impacto na saúde e bem-estar dos seus empregados, sendo que esses empregados têm influência na efetividade da organização como um todo (WILSON et al., 2004). Isso demonstra a importância de se estudar a saúde organizacional.

Os primeiros conceitos de saúde organizacional surgiram na década de 1950, relacionados com as noções de efetividade organizacional (GOMIDE Jr.; FERNANDES, 2008). Embora não exista, atualmente, uma abordagem única sobre efetividade, parece haver um consenso entre os pesquisadores de que esse é um tema central para as ciências da organização (CAMERON, 1986). Dessa forma, estudos sobre efetividade organizacional têm evoluído com a adoção geral de sistemas, referindo-se ao indivíduo, ao grupo e à organização como um sistema dinâmico interligado, sendo que alterações em uma ou mais partes desse complexo sistema implicam mudanças para os outros (McCANN, 2004).

Alguns fatores, segundo Cameron (1986), como inovação, proximidade aos clientes, lideranças participativas e a abordagem por objetivos têm sido apresentados como os mais importantes preditores de efetividade nas organizações. A preposição da abordagem de gestão por objetivos considerava a organização como efetiva conforme ela realizasse seus objetivos propostos. Segundo Gomide Jr. e Fernandes (2008), a efetividade foi concebida por autores como Argyris (1964) e Katz e Kahn (1966), como a maximização dos rendimentos organizacionais, a manutenção do sistema interno e a adaptação do sistema externo, determinada por uma combinação de eficiência da organização como um sistema. Gomide Jr. e Fernandes (2008) destacam ainda que, em consonância com Argyris, um novo construto na literatura sobre a saúde organizacional foi proposto, como por exemplo, por Bennis (1992), Schein (1965) e Fordice e Weill (1971), defendendo a ideia de organização saudável como aquela que apresentasse adaptabilidade, teste da realidade, senso de identidade e integração indivíduo-organização. 
Entretanto, conforme exposto por McCann (2004), duas importantes críticas emergiram das dimensões de efetividade organizacional, definidas como agilidade e resiliência organizacional, que são exploradas em termos das suas implicações para profissionais de recursos humanos. Esses dois conceitos são relacionados, mas diferentes. Agilidade ajuda a gerir a organização rapidamente à mudança, enquanto a resiliência contribui para o gerenciamento das mudanças perturbadoras. Para esse autor, o elo que as organizações estão criando está gerando dependências mútuas, dando origem a novas formas de organização como as redes virtuais. Essa nova dinâmica pode estar associada à busca da efetividade organizacional e à otimização da eficácia de um conjunto de organizações interdependentes (McCANN, 2004). A agilidade e a resiliência são importantes para as organizações na permanência de sua competitividade, no entanto, seu exercício, como característica essencial, pode trazer consideráveis riscos ao desempenho da empresa (McCANN, 2004). Para o autor, desenvolvimento contínuo, investimento em capacidades adaptativas e habilidades adequadas às pessoas e grupos serão os determinantes de sucesso em uma organização.

Nesse sentido, Dejoy e Wilson (2003) enfatizam dois aspectos: (1) a promoção da saúde organizacional através da interação dos fatores individuais e organizacionais e; (2) como essa interação afeta a otimização do uso de recursos e pessoas na organização. Para eles, a premissa-chave da saúde organizacional é a maximização do capital humano pela otimização da qualidade de vida no trabalho dentro das empresas. Esses autores afirmam ainda que, tradicionalmente, a promoção de saúde organizacional procura identificar e gerenciar os fatores de riscos dos indivíduos. Na sua essência, as práticas da empresa, como crenças e valores estão relacionados com a saúde e bem-estar do trabalhador e com o sucesso organizacional que, por sua vez, são influentes níveis da sua cultura. Dessa forma, em última análise, a verdadeira mudança organizacional envolve alterar esses valores e crenças. Porém, essa mudança pode modificar os domínios da vida profissional, acarretando, por exemplo, um stress laboral, ocasionado por fatores como carga de trabalho, conflito de papéis, ambiguidade de papéis e controle (DEJOY; WILSON, 2003).

Frente a esses acontecimentos, despontam, nas organizações, programas de prevenção a doenças ocupacionais e de redução de níveis de stress, oferecidos comumente aos colaboradores. Segundo O'Donell (2001), a principal razão pela qual as empresas investem em programas de saúde 
ocupacional é a contenção dos custos com cuidados médicos, a melhora e aumento da produtividade e da imagem da organização. Ainda na percepção desse autor, o alto desempenho do ser humano se dá quando o mesmo está física e emocionalmente habilitado a trabalhar e sente prazer pelo trabalho que realiza. Desse modo, quando existem ambiguidades, inflexibilidades, conflitos, rivalidades, sobrecarga de trabalho e mau relacionamento com superiores, fatores que prejudicam a boa saúde organizacional (MUCHINSKY, 2003), tem-se como consequência o stress oriundo do trabalho.

Assim, frente à importância de se investigar a saúde organizacional, Gomide Jr. e Fernandes (2008) apresentam a Escala de Percepção de Saúde Organizacional - EPSaO), construída e validada por Gomide Jr. e colaboradores (1999), com o propósito de verificar a percepção dos empregados a respeito da saúde da organização. Esses autores basearam-se nos critérios de saúde organizacional, apontados por Bennis (1962), Shein (1965) e Fordyce e Weil (1971). Tal escala foi desenvolvida devido à confusão conceitual entre saúde organizacional e saúde do trabalhador, das abordagens contemporâneas ou da consideração de critérios externos de adaptação às mudanças e, devido à falta de testes empíricos sobre o tema.

\section{Reflexões Acerca do Stress noTrabalho}

A utilização da palavra stress, para representar qualquer tipo de aflição ou cansaço do corpo e da mente, tornou-se tão popular que é comum ouvir pessoas atribuindo, a situações que fujam da sua habitualidade, uma causa ou consequência de stress. Independente do uso, o termo é empregado quando se quer representar indivíduos aflitos, cansados ou irritados. Mais do que um estado de espírito, o stress é uma reação do indivíduo a uma adaptação e pode causar um conjunto de sintomas - físicos, psicológicos e comportamentais (ROSSI, 2007).

Segundo Limongi França e Rodrigues (2005), a utilização da palavra stress antecede, em séculos, seu uso sistemático ou científico, tendo sido identificadas diferentes origens etimológicas para ela. Para Cooper e Cartwright (1996), a raiz da palavra vem do latim stringere e tem como significado "espremer". Os autores mencionam que a palavra stress consta do vocabulário anglo-saxônico desde o Século XVII, usada para descrever 
"adversidade" ou "aflição". Nesse século, a definição passou a ser empregada para expressar pressão ou forte esforço do corpo humano. Porém, conforme Cooper e Cartwright (1996), a primeira tentativa científica para explicar o stress relacionado à saúde foi usada por Hans Selye em 1946, o qual descreveu três estágios com indivíduos em situações estressantes: um conjunto universal de reações e processos fisiológicos, criados por exigências do ambiente, resistência como estágio máximo de adaptação e a exaustão como mecanismo de colapso.

O stress é reconhecido como um dos riscos mais sérios ao bem-estar psicossocial do indivíduo (BATEMAN; STRASSER, 1983). Para Rossi (2007), estudos indicam que o ambiente de trabalho, a estrutura corporativa, a saúde organizacional e as diversas outras interações entre emprego e empregado contribuem para as respostas individuais de stress e tensão. Nesse sentido, ambientes não saudáveis podem preconizar níveis de stress com efeitos negativos para o trabalhador, assim como na sua satisfação profissional, produtividade e desempenho.

Abordando também o stress ocupacional, Jex (1998) citado por Paschoal e Tamayo (2004), o define em três aspectos: (1) estímulos estressores: referemse aos estímulos do ambiente de trabalho que exigem respostas adaptativas por parte do empregado e que excedem a sua habilidade de enfrentamento (coping); (2) respostas aos eventos estressores: referem-se às respostas (psicológicas, fisiológicas e comportamentais) que os indivíduos emitem quando expostos a fatores do trabalho que excedem sua habilidade de enfrentamento; (3) estímulos estressores-respostas: referem-se ao processo geral em que demandas do trabalho têm impacto nos empregados.

Nessa mesma linha, Paschoal e Tamayo (2004) afirmam que, de acordo com a conceituação do stress ocupacional, a partir do enfoque nos estressores organizacionais, é possível diferenciar dois tipos de estudos: os de stress ocupacional e os de stress em geral. Os primeiros enfocam estressores relacionados ao ambiente de trabalho e os últimos, estressores gerais na vida do indivíduo. Em relação aos estressores ocupacionais, eles podem ser de natureza física, por exemplo, barulho, ventilação e iluminação no local de trabalho ou psicossocial, isto é, baseados nos papéis, nos fatores intrínsecos ao trabalho, nos aspectos de relacionamento interpessoal, autonomia e controle, e fatores relacionados ao desenvolvimento da carreira. Já os estressores gerais são relacionados a um estado interno que resulta da interação do organismo com estímulos ou circunstâncias nocivas, isto é, 
um estado dinâmico no interior do organismo (LAZARUS; FOLKMAN, 1984 apud LIMONGI-FRANÇA; RODRIGUES, 2005).

Sobre os papéis destacados por Paschoal e Tamayo (2004), existentes no ambiente de trabalho, tais papéis são considerados os construtos de Jex (1998) que afirma que dois fatores principais constituem essa categoria: o primeiro está relacionado ao conflito de papéis, o qual ocorre quando informações advindas de um membro ou contexto de trabalho entra em conflito com as informações de outro membro ou contexto. Com relação aos fatores intrínsecos ao trabalho, Travers e Cooper (1996) afirmam que eles se referem a aspectos como condições físicas de trabalho, níveis de participação e tomada de decisão e sobrecarga de trabalho. A sobrecarga de trabalho diz respeito a excesso de tarefas, tempo insuficiente para realizá-las e falta de recursos para fazer bem o trabalho (ROSSI; PERREWÉ; SAUTER, 2007).

Dando seguimento aos principais estressores relativos ao ambiente organizacional, as categorias como relacionamento interpessoal e desenvolvimento da carreira são conceituadas, respectivamente, como as interações entre as pessoas que compõe um grupo de trabalho, sejam colegas em um mesmo nível hierárquico, superiores e subordinados, ou entre empregados e clientes; e como aos aspectos relacionados à falta de estabilidade e insegurança no trabalho, bem como medo de obsolescência frente às mudanças tecnológicas e poucas perspectivas de promoções e crescimento de carreira (JEX; ELACQUA, 1999; TRAVERS; COOPER, 1996).

O último tipo de estressor, comumente relacionado ao controle/ autonomia no trabalho, Karasek (1979) publicou o modelo DemandaControle, prevendo que os trabalhadores que se defrontam com alta sobrecarga de exigências (ou pressões psicológicas), combinada com um baixo controle sobre o trabalho, correm maior risco de apresentar problemas de saúde física e mental decorrentes do stress. Enfatizando tal conceito, Maslach (2007) declara que a falta de controle no trabalho pode resultar de uma série de fatores e os empregados que são microgerenciados e que não têm permissão de usar sua própria sabedoria ou experiência para tomar decisões sentirão a falta de arbítrio pessoal e a falta de autonomia em seu trabalho.

Além das concepções abordadas sobre stress ocupacional, Cooper e Cartwright (1996) relacionam as reações associadas a estressores como sendo de natureza emocional. Eles se referem às emoções destrutivas e ao stress como se fosse um único construto e afirmam que futuramente o estudo de stress no trabalho poderá ser substituído pelo estudo das emoções no trabalho. 
Em complemento a essas abordagens, Paschoal e Tamayo (2004) mencionam que, em quase todos os estudos, encontram-se inúmeras variáveis de natureza pessoal e situacional que podem influenciar o stress ocupacional, independentemente da definição adotada para esse construto. Quanto às variáveis situacionais, destaca-se o suporte social encontrado pelo trabalhador, o qual pode ser recebido do supervisor, colegas de trabalho e de outras pessoas fora do ambiente de trabalho. Quanto às variáveis pessoais, o estilo de enfrentamento (coping) empregado frente aos elementos estressores consiste na principal variável individual, representando ainda um ponto central de muitos estudos.

Assim, frente à relevância das disposições sobre o stress ocupacional e à insuficiência de instrumentos que atendam aos parâmetros psicométricos e aos postulados teóricos do assunto, Paschoal e Tamayo (2004) construíram e validaram um questionário para mensurar o stress ocupacional, que pode ser utilizado em diversos ambientes de trabalho e para ocupações variadas a Escala de Stress no Trabalho - EET. Essa escala pode ser aplicada como ferramenta no diagnóstico do ambiente de trabalho das organizações, orientando medidas que visem à qualidade de vida dos funcionários.

\section{Metodologia da Pesquisa}

Visando atingir aos objetivos propostos, optou-se por realizar um estudo quantitativo de cunho descritivo, através de uma survey, estratégia que busca descobrir fatos, determinar atitudes e opiniões, e ajudar a entender comportamentos, utilizando-se da avaliação, análise e descrição de uma população baseada em uma amostra (BAKER, 2001). O questionário utilizado para a coleta de dados foi dividido em três partes: a primeira busca identificar aspectos de perfil da população investigada, tal como idade, gênero, escolaridade, estado civil, função que exerce no restaurante e tempo de atuação na empresa; a segunda parte visa levantar os fatores relativos ao stress no trabalho, e a última identifica os aspectos relacionados à saúde organizacional.

Para a elaboração da segunda parte do questionário adaptou-se a Escala de stress no Trabalho - EET, de autoria de Paschoal e Tamayo (2004), constituída por 23 questões dispostas em escala tipo likert de cinco pontos, variando de 1 "discordo totalmente" a 5 "concordo totalmente". Assinala-se 
que uma pequena alteração foi efetuada neste instrumento, transformando a questão inicialmente descrita como "Fico irritado com discriminação, e/ou favoritismo no meu ambiente de trabalho", em duas afirmativas: "Fico irritado com a discriminação no meu ambiente de trabalho" e "Fico irritado com o favoritismo no meu ambiente de trabalho". Tal mudança foi realizada devido à compreensão de que a afirmativa destacada no estudo original apresentava mais de uma variável para ser analisada, o que poderia gerar certa dúvida nos respondentes no momento em que fossem preencher o instrumento.

Já com relação à identificação dos fatores relativos à saúde organizacional, adotou-se, com algumas alterações, a Escala de Percepção de Saúde Organizacional - EPSaO, de Gomide Jr. et al. (1999), apresentada por Gomide Jr. e Fernandes (2008). Para essa escala, as modificações realizadas concernem à forma como as afirmativas estavam descritas, ou seja, algumas frases foram reescritas, com vocabulário mais simples, porém buscando-se conservar seu sentido e essência. Essas alterações foram necessárias devido ao vocabulário culto-padrão apresentado, que poderia interferir na interpretação dos respondentes. Salienta-se, entretanto, que o número (27) e a ordem de disposição das questões mantiveram-se inalteradas, bem como a escala utilizada (tipo likert de cinco pontos, variando de 1 "discordo totalmente" a 5 "concordo totalmente").

A população investigada foi composta por funcionários de restaurantes públicos e privados da cidade de Santa Maria, localizada na região central do Rio Grande do Sul. A escolha dessa população decorreu do fato desse ambiente laboral gerar fadiga, esforço físico, sobrecarga de trabalho, pressão do tempo, entre outros fatores estressantes, que acompanham o trabalho desses profissionais (CABRAL, 2009). Salienta-se que todos os restaurantes públicos da cidade foram investigados (Restaurante Popular, Restaurante do Hospital da Universidade Federal de Santa Maria e o Restaurante Universitário da mesma instituição). Em relação aos restaurantes privados, selecionou-se uma rede de restaurantes da cidade composta por três unidades e mais um restaurante escolhido aleatoriamente visto que a investigação somente dos colaboradores da rede de restaurantes poderia distorcer os resultados, devido aos aspectos culturais da organização.

No que tange a análise de resultados, essa análise foi realizada com o apoio de alguns testes estatísticos, como o teste te Qui-quadrado, na primeira subseção, que visava descrever a amostra investigada. Já nas duas subseções seguintes, que tinham o objetivo de detalhar os aspectos relativos aos fatores 
de stress no trabalho e de saúde organizacional, inicialmente realizou-se uma análise fatorial exploratória, a qual analisou-se a estrutura de inter-relações (covariâncias) existentes entre um grande número de variáveis com a definição de uma série de dimensões subjacentes comuns, conhecidas como fatores (HAIR et al., 2005). Ainda, buscou-se identificar a confiabilidade interna para cada fator formado, através do Coeficiente Alpha-Cronbach. Finalmente, para identificar se houve diferença de médias, entre os restaurantes públicos e privados, para os fatores formados, aplicou-se, novamente, um teste t para amostras independentes.

Na quarta subseção da análise de resultados, que visava identificar a relação entre os fatores de stress ocupacional e saúde organizacional, efetuouse uma análise de correlação, a qual envolveu a mensuração da força de uma relação entre essas duas variáveis (AAKER, KUMAR; DAY, 2004). Na última subseção da análise de resultados, realizou-se uma análise de regressão, a fim de atingir o objetivo geral deste trabalho. De acordo com Malhotra (2006), a análise de regressão é um processo poderoso e flexível para a verificação de relações associativas entre uma variável métrica dependente e uma ou mais variáveis independentes.

Para o modelo de regressão estimado, foram testados os pressupostos de normalidade, autocorrelação, multicolinearidade e homocedasticidade. Para verificar a normalidade do erro, realizou-se o teste de KolmogorovSmirnov - KS sob a hipótese nula de que a distribuição da série testada é normal. A detecção da autocorrelação entre os resíduos da regressão foi verificada através do teste Durbin Watson que, conforme Gujarati (2006), é o teste adequado para testar a presença de correlação serial, sendo a hipótese nula do teste a ausência de autocorrelação.

A premissa da multicolinearidade dos fatores foi verificada através da tolerância - TOL, que deve ser maior do que 0,10 e do índice de condição, que deve ser menor do que 15. Finalmente, para atender ao pressuposto da homocedasticidade, aplicou-se o teste de Pesaran-Pesaran, desenvolvido para verificar se a variância dos resíduos mantém-se constante em todo o espectro das variáveis independentes (CORRAR; PAULO; DIAS FILHO, 2007).

Para o processamento e análise dos dados foram utilizados os softwares "Windows Excel ${ }^{\circledR "}$ e "Statistical Package for the Social Sciences - SPSS 10.0". 


\section{Análise dos Resultados}

Esta seção será dividida em cinco partes. Inicialmente, foram descritos os aspectos relativos à amostra pesquisada. Na segunda parte, explorou-se a análise fatorial relativa aos construtos de stress ocupacional, bem como a diferença de médias para cada um dos fatores entre os restaurantes públicos e privados. A mesma análise foi realizada na terceira parte, porém para os construtos de saúde organizacional. Na quarta subseção, esses fatores foram submetidos a uma análise de correlação, a fim de verificar a relação entre eles. Finalmente, na última parte, investigou-se a influência da percepção de saúde organizacional sobre o stress no trabalho dos funcionários de restaurantes da cidade de Santa Maria - RS.

\subsection{Análise Descritiva da Amostra}

A amostra investigada foi composta por 140 funcionários de restaurantes públicos e privados. Dentre os quais, $43,2 \%$ são do sexo masculino e $56,8 \%$ do sexo feminino. Sobre a escolaridade da amostra geral investigada, percebese que a maioria possui Ensino Médio completo (24,3\%), seguido do Ensino Médio incompleto (23,5\%). A função mais representativa foi a de garçom $(24,3 \%)$, seguida de copeiros (15,7\%). Salienta-se que, através do teste quiquadrado, com $95 \%$ de confiança, as funções desempenhadas nos restaurantes públicos são predominantemente de garçons, enquanto, nos restaurantes privados, há distintas funções, como as de chef, saladeira, copeiro, etc. Quanto à idade dos entrevistados, obteve-se uma média de 36,84 anos, já com relação ao estado civil dos respondentes, predominaram pessoas casadas $(39,6 \%)$.

A amostra dos restaurantes públicos é de 76 pessoas, de três restaurantes distintos: 11 funcionários do Restaurante Popular, 42 do Restaurante Universitário - UFSM e 23 do Restaurante do Hospital Universitário - UFSM. Essas pessoas possuem em média 42,37 anos e 10,95 anos de trabalho no mesmo restaurante, período considerável quando comparado ao dos restaurantes privados $(3,11)$, o que está associado ao fato de a maioria desses funcionários serem concursados. Ressalta-se que tais diferenças foram significativas, com $95 \%$ de confiança, através do teste $\mathbf{t}$. Com relação ao gênero dos funcionários desses restaurantes, 56 são mulheres $(74,7 \%)$ e 19 homens $(25,3 \%)$. O fato de serem concursados também pode ser responsável pela maioria dos respondentes possuírem Ensino Médio completo $(23,7 \%)$ e 
Ensino Superior completo (18,4\%), percentual composto, em grande parte, pelas nutricionistas que atuam junto a essas instituições. No que tange à escolaridade e à função exercida pelos funcionários, pode-se inferir que, através do Qui-quadrado, com 95\% de confiança, os funcionários dos restaurantes públicos possuem maior escolaridade do que os demais.

Já os 64 funcionários dos restaurantes privados são oriundos de quatro empresas distintas, sendo que três delas pertencem a uma mesma rede. A idade média dessas pessoas é de 30,44 anos e o tempo médio de trabalho de 3,11 anos, o que diverge consideravelmente dos resultados encontrados nos restaurantes públicos. Uma das possíveis causas para o menor tempo de trabalho desses funcionários, é que, muitas vezes, alguns aspectos como rotação de turnos, longas jornadas de trabalho, duração indefinida da jornada e atividade física corporal excessiva, citados por Villalobos (1999), podem ocasionar stress oriundo do trabalho e o consequente afastamento do colaborador. Outro aspecto verificado foi o de que a maioria dos respondentes possui Ensino Médio incompleto (28,3\%), e que apenas 5\% concluíram o Ensino Superior, sendo estes os gerentes e os proprietários. Nota-se, assim, que os funcionários dos restaurantes públicos apresentam mais qualificação do que os dos privados, sendo que os restaurantes privados empregam apenas o mínimo exigido em lei de profissionais graduados, como nutricionistas.

\subsection{Análise Fatorial da Percepção de Stress no Trabalho}

O instrumento utilizado para mensurar a percepção de stress no trabalho dos funcionários de restaurantes da cidade de Santa Maria foi adaptado de Paschoal e Tamayo (2004). As 24 questões que o compõem estão destacadas no Quadro 1. A fim de facilitar a análise, um código correspondente para cada questão foi criado e destacado nesse Quadro, bem como a carga fatorial para cada uma das variáveis investigadas e a variância explicada para cada fator. Destaca-se que o Quadro 1 expõe os fatores formados através da análise fatorial rotacionada, que teve como método utilizado para a extração dos fatores a análise dos componentes principais e da rotação Varimax com normalização Kaiser.

Inicialmente, para se verificar a adequação da utilização da análise fatorial, foi necessária a verificação do KMO e do teste de Bartlet. O índice de KaiserMeyer-Olkin $(\mathrm{KMO}=0,871)$ de adequação da amostra e o teste de esfericidade de Barlett (significativo a $\mathrm{p}<0,001$ ) indicaram a fatorabilidade dos dados. 
Após a verificação da adequação da análise fatorial, partiu-se para a identificação das comunalidades apresentadas para cada uma das questões dispostas. Foi necessária a retirada de três questões do instrumento, pois essas variáveis apresentaram comunalidade menor do que 0,5 , valor que mede a proporção da variância explicada pelo fator, e que, por regra prática, deve ser maior do que 0,5 para cada questão (LATIF, 1994).

Finalmente, para a determinação do número de fatores, observou-se a análise da variância total explicada, que deve atingir no mínimo $60 \%$ da variância acumulada e autovalores maiores do que 1 (MALHOTRA, 2006). A análise da porcentagem de variância mostrou que o instrumento compreende cinco fatores, que explicam $64,95 \%$ da variância acumulada, todos com autovalores maiores do que 1 . Observa-se que, em todos os fatores, foram selecionadas as variáveis com carga fatorial superior a 0,40, o que indica que elas são representantes úteis dos fatores, e quanto maior a carga fatorial, melhor o item (AVRICHIR; DEWES, 2006). No Quadro 1, pode-se visualizar a variância explicada e a carga fatorial para cada um dos fatores.

\begin{tabular}{|c|c|c|}
\hline Questão & Carga & Variância \\
\hline O tipo de controle existente em meu trabalho me irrita. & 0,827 & \\
\hline A falta de autonomia na execução do meu trabalho tem sido desgastante. & 0,803 & \\
\hline Tenho me sentido incomodado com a falta de confiança de meu superior no meu trabalho. & 0,699 & \\
\hline A forma como as tarefas são distribuídas em minha área tem me deixado nervoso. & 0,611 & $38,20 \%$ \\
\hline A comunicação existente entre mim e meu superior me deixa incomodado. & 0,595 & \\
\hline Fico incomodado com a falta de informações sobre minhas tarefas. & 0,463 & \\
\hline \multicolumn{3}{|l|}{ Fator 1: Autonomia/controle (alpha $=0,8361)$} \\
\hline Fico irritado por não saber direito quais são as minhas responsabilidades neste trabalho. & 0,750 & \\
\hline Fico incomodado porque meu chefe não me atribui tarefas importantes. & 0,603 & \\
\hline A competição no meu ambiente de trabalho tem me deixado de mau humor. & 0,552 & $8,51 \%$ \\
\hline Fico de mau humor por me sentir isolado na empresa. & 0,546 & \\
\hline Fico nervoso quando recebo ordens contraditórias do meu superior. & 0,504 & \\
\hline \multicolumn{3}{|l|}{ Fator 2: Papéis e ambiente de trabalho (alpha $=0,778$ ) } \\
\hline Quando meu chefe não valoriza o meu trabalho, diante dos meus colegas, fico aborrecido. & 0,746 & \\
\hline Quando meu superior me trata mal, na frente dos colegas, me sinto incomodado. & 0,737 & $6,67 \%$ \\
\hline Fico aborrecido quando tenho que realizar tarefas que estão além de minha capacidade. & 0,657 & \\
\hline Fico indignado com o favoritismo no meu ambiente de trabalho & 0,578 & \\
\hline
\end{tabular}

Quadro 1: Questões que compõem cada um dos fatores de stress no trabalho, carga fatorial e variância explicada. Fonte: Elaborado pelo autor 


\begin{tabular}{|l|c|c|}
\hline \multicolumn{1}{|c|}{ Questão } & Carga & Variância \\
\hline Fator 3: Relacionamento com o chefe (alpha = 0,7684) & 0,753 & 0,643 \\
\hline Fico irritado com a falta de comunicação entre mim e meus colegas de trabalho. & $6,22 \%$ \\
\hline Fico nervoso quando não tenho tempo suficiente para terminar todo o meu trabalho. & 0,481 & \\
\hline Fico irritado com a discriminação no meu ambiente de trabalho. & 0,746 & \\
\hline Fator 4: Relações interpessoais (alpha = 0,631) & 0,624 & $5,35 \%$ \\
\hline As poucas perspectivas de crescimento na carreira me deixam angustiado. & 0,602 & \\
\hline Tenho me sentido incomodado por trabalhar em tarefas abaixo do meu nível de habilidade. & & \\
\hline Fico irritado por ser pouco valorizado por meus chefes. & & \\
\hline Fator 5: Crescimento e valorização (alpha = 0,779) & & \\
\hline
\end{tabular}

Quadro 1: Questões que compõem cada um dos fatores de stress no trabalho, carga fatorial e variância explicada

Fonte: Elaborado pelo autor

O primeiro fator, composto por seis variáveis, possui variância explicada de 38,20\%, e foi denominado de "Autonomia/Controle", em decorrência das questões que o compõem. Esse fator relaciona-se com o que McDonald e Shaver (1981) consideram como causas intrínsecas que podem comprometer a satisfação do funcionário no trabalho: o trabalho em si, a supervisão ineficiente, a falta de controle, a sobrecarga de trabalho e a exaustão física.

No segundo fator, denominado "Papéis e Ambiente de Trabalho", as variáveis relacionam-se, principalmente, com as tarefas e a forma como o indivíduo as executa. Muchinsky (2003) destaca que uma interpretação extrínseca ao trabalho produz o sentimento de aprovação e desaprovação, afeição e antipatia, as quais constituem a atitude de satisfação e insatisfação do (com e no) emprego.

O terceiro fator, com quatro variáveis, possui variância de $6,67 \%$, e foi denominado "Relacionamento com o Chefe". As variáveis que o compõem estão de acordo com o que Martinez (2006) destaca, ao sumarizar a posição de diversos autores: entre os diversos fatores psicossociais do ambiente de trabalho que podem configurar cargas mentais inadequadas para o trabalhador estão os conflitos de papéis, os conflitos com chefias, o tipo de atitude da chefia, o medo de errar ou falhar, a pressão de tempo, o volume de trabalho, a restrição no uso das habilidades e conhecimento, a limitação no controle sobre o próprio trabalho, etc. 
O quarto fator "Relações Interpessoais" $(6,22 \%)$, e o quinto fator "Crescimento e Valorização" (5,35\%), possuem três variáveis cada um. Sobre as variáveis do fator quatro, Bom Sucesso (1997) discorre que a valorização do ser humano, a preocupação com sentimentos e emoções, e com a qualidade de vida são fatores que fazem a diferença. O trabalho é a forma como o homem, por um lado, interage e transforma o meio ambiente, assegura a sobrevivência, e, por outro lado, estabelece relações interpessoais que, teoricamente, serviriam para reforçar a sua identidade e o senso de contribuição. Ainda, para Peiro (1993 apud BERNSTORFF, 2007), a qualidade das relações interpessoais como falta de coesão ou confiança entre o grupo de trabalho é um importante potencial de stress. Já no último fator vislumbrado, as variáveis são relacionadas aos aspectos de valorização no ambiente de trabalho e crescimento profissional. De acordo com Brown (1996), uma situação de envolvimento com o trabalho revela engajamento do indivíduo para com o seu trabalho e pode prevenir futuros problemas entre o indivíduo e a organização.

Após a descrição dos cinco fatores, faz-se necessário analisar o grau de consistência, ou seja, a confiabilidade dos construtos. Dessa forma, foi medido o Alfa de Cronbach de cada fator. Tal procedimento apresentou resultados aceitáveis, ou seja, maiores do que 0,6, indicando a consistência interna dos fatores (MALHOTRA, 2006). Para o fator "Autonomia/Controle" foi retirada uma variável, a fim de melhorar o valor do alpha, sendo que isso resultou em 0,8631 .

Realizada a verificação da composição de cada um dos fatores de stress no trabalho, buscou-se comparar as médias dos restaurantes públicos e privados, a fim de atingir parcialmente o segundo objetivo. Na Tabela 1, estão expostas as médias, os desvios-padrões e o Teste t para amostras independentes que visa identificar se há diferença entre as médias apresentadas para os fatores dos restaurantes públicos e dos restaurantes privados. Ressalta-se que, anteriormente à aplicação do teste $\mathbf{t}$, aplicou-se o teste $\mathbf{F}$ para avaliar a hipótese de igualdade das variâncias dos dois grupos. Para o fator "Autonomia/Controle" rejeitou-se a hipótese de igualdade de variâncias, aplicando-se o teste t heterocedástico, enquanto que para os demais fatores foi constatada a igualdade entre as variâncias, aplicando-se o teste $\mathbf{t}$ homocedástico. 
Tabela 1: Média e desvio-padrão dos fatores de stress no trabalho para os restaurantes públicos e privados e valor e significância do teste t para amostras independentes

\begin{tabular}{|l|c|c|c|c|c|c|}
\hline \multirow{2}{*}{$\begin{array}{l}\text { Fatores do Stress no } \\
\text { Trabalho }\end{array}$} & \multicolumn{2}{|c|}{ Público } & \multicolumn{2}{c|}{ Privado } & \multicolumn{2}{c|}{ Teste T } \\
\cline { 2 - 7 } & Média & Desvio & Média & Desvio & Valor & Sig \\
\hline Autonomia/controle & 2,62 & 1,09 & 2,37 & 0,85 & 1,495 & 0,137 \\
\hline Papéis e ambiente de trabalho & 2,69 & 1,01 & 2,49 & 0,81 & 1,216 & 0,226 \\
\hline Relacionamento com o chefe & 3,10 & 1,15 & 3,23 & 0,97 & $-0,682$ & 0,496 \\
\hline Relações interpessoais & 3,10 & 1,05 & 2,60 & 0,95 & 2,921 & 0,004 \\
\hline Crescimento e valorização & 2,98 & 1,14 & 3,03 & 1,15 & $-0,213$ & 0,832 \\
\hline Stress geral & 2,90 & 0,92 & 2,74 & 0,66 & 1,153 & 0,251 \\
\hline
\end{tabular}

Fonte: Elaborada pelos autores

Nota-se que somente o Fator 4 (relações interpessoais) apresenta diferença de médias significativa. Esse fator, composto pelas variáveis "falta de comunicação, tempo insuficiente para terminar o trabalho e discriminação", está gerando mais stress ocupacional nos funcionários dos restaurantes públicos. Tal fato pode estar relacionado à alta escolaridade dos funcionários dos restaurantes públicos, ocasionado maiores exigências por parte deles no ambiente de trabalho, que, ao não serem satisfeitas, podem gerar tensão e stress.

\subsection{Análise Fatorial da Percepção de Saúde Organizacional}

Para mensurar a percepção dos funcionários com relação à saúde organizacional, baseou-se a análise na EPSaO, de Gomide Jr. et al. (1999) e presente em Gomide Jr. e Fernandes (2008). O procedimento para a realização da análise fatorial da percepção de saúde organizacional foi semelhante ao da fatorial de stress no trabalho. O método utilizado para a extração dos fatores foi o do eixo principal e a rotação Varimax com normalização Kaiser. $\mathrm{O}$ índice de Kaiser-Meyer-Olkin - KMO obteve um valor de 0,834 e o teste de esfericidade de Barlett foi significativo, indicando a fatorabilidade dos dados.

Com relação às comunalidades, três variáveis, das 27 , tiveram que ser eliminadas, visto que obtiveram valor menor do que 0,5 . Após as exclusões, o instrumento passou a ter seis fatores, todos com autovalores maiores do que 1 e variância acumulada de 62,42\% (Quadro 2). 


\begin{tabular}{|c|c|c|}
\hline Questão & Carga & Variância \\
\hline As pessoas procuram ajudar seus colegas por meio de ações concretas. & 0,698 & \multirow{8}{*}{$33,28 \%$} \\
\hline Os funcionários trabalham em conjunto para solucionar crises da empresa. & 0,693 & \\
\hline As pessoas procuram ajudar seus colegas por meio de sugestões. & 0,661 & \\
\hline As pessoas têm respeito umas pelas outras. & 0,657 & \\
\hline As pessoas cooperam para realizar os trabalhos. & 0,566 & \\
\hline As pessoas procuram ajudar os colegas que têm mau desempenho no trabalho. & 0,540 & \\
\hline As pessoas confiam umas nas outras. & 0,500 & \\
\hline \multicolumn{2}{|l|}{ Fator 1: Integração de pessoas e equipes (alpha $=0,8287$ ) } & \\
\hline As inovações são buscadas continuamente. & 0,762 & \multirow{7}{*}{$7,78 \%$} \\
\hline As pessoas preparam-se para o futuro, estando atentas aos novos métodos de trabalho. & 0,686 & \\
\hline As pessoas encaram o trabalho como algo prazeroso. & 0,603 & \\
\hline Os procedimentos são estabelecidos de modo a ajudar as pessoas a serem eficazes no trabalho. & 0,551 & \\
\hline A competição entre as equipes da empresa é feita de maneira honesta. & 0,528 & \\
\hline As pessoas encaram seus trabalhos como algo importante. & 0,471 & \\
\hline \multicolumn{2}{|l|}{ Fator 2: Inovação e eficiência (alpha = 0,8346) } & \\
\hline Os problemas percebidos podem ser comentados diretamente com as pessoas envolvidas. & 0,774 & \multirow{4}{*}{$6,30 \%$} \\
\hline $\begin{array}{l}\text { As necessidades individuais são levadas em consideração quando é preciso diagnosticar } \\
\text { problemas da empresa. }\end{array}$ & 0,686 & \\
\hline Quando um problema ocorre, todas as pessoas envolvidas podem opinar sobre uma solução. & 0,603 & \\
\hline \multicolumn{2}{|l|}{ Fator 3: Envolvimento interpessoal (alpha $=0,7032)$} & \\
\hline As pessoas têm acesso às informações necessárias para tomar decisões relativas ao trabalho. & 0,676 & \multirow{5}{*}{$5,40 \%$} \\
\hline As pessoas sabem o que é importante para a empresa. & 0,563 & \\
\hline As ações, nesta empresa, são planejadas em equipe. & 0,520 & \\
\hline Há um sentimento geral de liberdade na empresa. & 0,493 & \\
\hline \multicolumn{2}{|l|}{ Fator 4: Organização saudável (alpha = 0,6274) } & \\
\hline Os chefes variam seus estilos de administração conforme as situações de trabalho. & 0,754 & \multirow[t]{3}{*}{$5,09 \%$} \\
\hline Os procedimentos da empresa se adaptam rapidamente às mudanças. & 0,563 & \\
\hline \multicolumn{2}{|l|}{ Fator 5: Adaptabilidade a mudanças (alpha $=0,4409$ ) } & \\
\hline As pessoas conhecem os objetivos que a empresa pretende alcançar. & 0,858 & \multirow[t]{3}{*}{$4,57 \%$} \\
\hline As pessoas trabalham unidas para que a empresa atinja os seus objetivos. & 0,467 & \\
\hline Fator 6: Objetivos organizacionais (alpha $=0,5030)$ & & \\
\hline
\end{tabular}

Quadro 2: Código, questões que compõem cada um dos fatores de saúde organizacional, carga fatorial e variância explicada

Fonte: Elaborado pelo autor 
O primeiro fator, denominado "Integração de pessoas e equipes", foi composto por sete variáveis e apresentou variância explicada de 33,28\%. Esse fator expressa, de acordo com Keyes (1998) e Keyes, Hysom e Lupo (2000), a dimensão integração social como sendo a qualidade da relação entre o indivíduo e o ambiente em que ele está inserido. É também o sentimento de fazer parte de uma comunidade, perceber suporte, compartilhar com outros e observar que possui coisas em comum com outras pessoas. Acrescenta-se ainda, que esse fator possui nome semelhante ao dado por Gomide Jr. et al. (1999 apud GOMIDE Jr. e FERNANDES, 2008), por apresentar algumas das variáveis presentes no estudo original.

No fator "Inovação e eficiência" (7,78\%), percebe-se que as seis variáveis nele inseridas ilustram que a saúde organizacional possui relação com a busca de inovação e eficiência no ambiente laboral. Harter, Schmidt e Keyes (2002) expressam que, nas empresas em que os funcionários relatam, por exemplo, maiores níveis de satisfação com o ambiente de trabalho, desenvolvimento pessoal por meio do trabalho, relações amistosas em decorrência dele, revelam também níveis mais altos de lealdade, lucratividade, produtividade e retenção. Nota-se, assim, que os aspectos relacionados à boa saúde organizacional influenciam os colaboradores de modo a incrementar a sua efetividade.

Quanto ao terceiro fator, "Envolvimento interpessoal", nota-se a congruência de afirmativas referentes ao envolvimento de todas as pessoas da organização. Para Jaffe (1995), as organizações que investem no atendimento das necessidades individuais conseguem mais comprometimento e produtividade, beneficiando tanto a organização quanto o funcionário.

O quarto fator, "Organização saudável", incorpora aspectos de liberdade no trabalho, bom fluxo de informações e busca de objetivos em comum. Tal fator vai ao encontro do que Fordyce e Weil (1971) destacam como sinais de uma organização saudável: compartilhamento dos objetivos da organização, existência de um ambiente onde as pessoas se sintam à vontade para falar sobre os problemas diretamente com os responsáveis, ênfase em resoluções práticas dos problemas, determinação de que as decisões são tomadas segundo a competência, a distribuição de responsabilidades e a organização do trabalho.

Os fatores de número cinco e seis foram compostos por duas variáveis e possuem variância explicada de 5,09\% e 4,57\%, respectivamente. O quinto fator, "Adaptabilidade a mudanças", abrange questões que corroboram a afirmação de Cox e Howarth (1990), de que o conceito de saúde 
organizacional foi desenvolvido para indicar se a organização é efetiva em relação a muitos ambientes diferentes e se é capaz de reagir a mudanças nas circunstâncias ambientais. Já o sexto fator, "Objetivos organizacionais", expõe que há inter-relação entre os componentes do sistema de trabalho e o estado de saúde da organização, o que combina efetividade na realização dos objetivos desejados e bem-estar - qualidade de vida dos membros organizacionais (SHOAF et al., 2004).

Para verificar a confiabilidade interna dos seis fatores destacados, efetuou-se o teste do alfa de Crombach para cada um deles, como pode ser visualizado na Tabela 2. Nessa Tabela, ainda são apresentadas as médias finais para os fatores. Ressalta-se que os fatores "Integração de pessoas e equipes, Inovação e eficiência, Envolvimento interpessoal e Organização saudável" apresentaram alfas maiores do que 0,6 e são mantidos. Para os fatores "Adaptabilidade a mudanças e Objetivos organizacionais", como os alfas foram inferiores ao valor mínimo sugerido, optou-se pela eliminação dos mesmos.

Bem como foi realizado com os fatores de stress no trabalho, através do teste $\mathbf{t}$ (Tabela 2), contemplou-se o objetivo de verificar a existência de diferença entre os fatores de percepção de saúde organizacional que afetam os funcionários dos restaurantes públicos e privados.

Tabela 2: Média e desvio-padrão dos fatores de saúde organizacional para os restaurantes públicos e privados e valor e significância do teste t para amostras independentes

\begin{tabular}{|l|c|c|c|c|c|c|}
\hline \multirow{2}{*}{$\begin{array}{l}\text { Fatores da Saúde } \\
\text { Organizacional }\end{array}$} & \multicolumn{2}{|c|}{ Público } & \multicolumn{2}{c|}{ Privado } & \multicolumn{2}{c|}{ Teste T } \\
\cline { 2 - 7 } & Média & Desvio & Média & Desvio & Valor & Sig \\
\hline Integração de pessoas e equipes & 3,09 & 0,75 & 2,85 & 0,93 & 1,735 & 0,085 \\
\hline Inovação e eficiência & 3,15 & 0,78 & 3,24 & 0,86 & $-0,621$ & 0,536 \\
\hline Envolvimento interpessoal & 3,17 & 0,93 & 3,05 & 1,04 & 0,742 & 0,459 \\
\hline Organização saudável & 3,03 & 0,75 & 3,02 & 0,88 & 0,046 & 0,963 \\
\hline Adaptabilidade a mudanças & 3,24 & 0,91 & 3,15 & 0,88 & 0,6 & 0,549 \\
\hline Objetivos organizacionais & 2,99 & 0,93 & 3,06 & 1,14 & $-0,426$ & 0,671 \\
\hline Saúde geral & 3,11 & 0,65 & 3,04 & 0,75 & 0,611 & 0,542 \\
\hline
\end{tabular}

Fonte: Elaborada pelos autores 
Nenhum dos fatores observados apresentou diferença significativa entre os restaurantes públicos e privados. Nota-se, ainda, que todas as médias apresentam valores em torno de 3 , indicando que tanto os funcionários dos restaurantes públicos, quanto os dos privados, possuem opinião semelhante, ou seja, posicionamento indiferente, com relação a cada um dos fatores que compóem o construto de saúde organizacional.

\subsection{Análise de Correlação entre os Fatores Saúde e Stress}

A fim de verificar a relação entre a percepção dos fatores de stress ocupacional e de saúde organizacional, calculou-se o Coeficiente de Correlação de Pearson, disposto na Tabela 3. Ainda, nesta tabela, é apresentada a correlação dos fatores gerais (média dos fatores que compõem o fator) para ambos os construtos.

Como se pode perceber, todas as correlações entre os fatores de stress e saúde foram significativas, com exceção da correlação entre os fatores Saúde2 e Saúde3 com Stress3.

Tabela 3: Correlação entre os fatores de stress ocupacional, saúde organizacional e tempo de serviço

\begin{tabular}{|l|l|l|l|l|l|l|l|l|l|l|}
\hline Fator & Stress2 & Stress3 & Stress4 & Stress5 & Saúde1 & Saúde2 & Saúde3 & Saúde4 & Geral Saúde & Geral Stress \\
\hline Stress1 & $0,675^{* *}$ & $0,455^{* *}$ & $0,468^{* *}$ & $0,588^{* *}$ & $-0,348^{* *}$ & $-0,495^{* *}$ & $-0,286^{* *}$ & $-0,344^{* *}$ & $-0,449^{* *}$ & $0,803^{* *}$ \\
\hline Stress2 & & $0,537^{* *}$ & $0,582^{* *}$ & $0,566^{* *}$ & $-0,366^{* *}$ & $-0,344^{* *}$ & $-0,24^{* *}$ & $-0,322^{* *}$ & $-0,388^{* * *}$ & $0,843^{* *}$ \\
\hline Stress3 & & & $0,467^{* *}$ & $0,505^{* *}$ & $-0,228^{* *}$ & $-0,120$ & $-0,098$ & $-0,344^{* *}$ & $-0,237^{* *}$ & $0,758^{* *}$ \\
\hline Stress4 & & & & $0,407^{* *}$ & $-0,303^{* *}$ & $-0,315^{* *}$ & $-0,184^{*}$ & $-0,312^{* *}$ & $-0,338^{* *}$ & $0,740^{* *}$ \\
\hline Stress5 & & & & & $-0,317^{* *}$ & $-0,306^{* *}$ & $-0,245^{* *}$ & $-0,363^{* *}$ & $-0,375^{* *}$ & $0,791^{* *}$ \\
\hline Saúde1 & & & & & & $0,634^{* *}$ & $0,503^{* *}$ & $0,574^{* *}$ & $0,829^{* *}$ & $-0,394^{* *}$ \\
\hline Saúde2 & & & & & & & $0,526^{* *}$ & $0,567^{* *}$ & $0,831^{* *}$ & $-0,395^{* *}$ \\
\hline Saúde3 & & & & & & & & $0,476^{* *}$ & $0,793^{* *}$ & $-0,265^{* *}$ \\
\hline Saúde4 & & & & & & & & & $0,794^{* *}$ & $-0,428^{* *}$ \\
\hline Geral Saúde & & & & & & & & & & $-0,451^{* *}$ \\
\hline
\end{tabular}

** e $e^{*}$ indicam respectivamente correlação significativa a $1 \%$ e $5 \%$

Fonte: Elaborada pelos autores

Nota-se, através da Tabela 3, que as correlações entre os fatores de stress ocupacional e saúde organizacional são sempre negativas, o que significa que, conforme aumenta a percepção de um dos fatores (saúde ou stress) diminui a percepção do outro, corroborando com a teoria que destaca que 
são medidas inversamente proporcionais. Conforme afirmam Tamayo et al. (2002 apud PASCHOAL; TAMAYO, 2004), o stress ocupacional se correlaciona negativamente com a percepção de saúde no trabalho, segurança e competência profissional. Acrescenta-se, também, que as correlações encontradas variaram de $-0,098$ a $-0,366$, consideradas baixas por Pestana $e$ Gageiro (2003). A correlação mais alta $(-0,366)$ encontrada é relativa aos fatores Saúde1 (Integração de pessoas e equipes) e Stress2 (Papéis e ambiente de trabalho), indicando que conforme se alteram as relações entre os colegas de trabalho, alteram-se também, em sentido oposto, a percepção do indivíduo quanto ao seu papel na empresa e às atividades que deve desempenhar. Conforme Corrêa e Menezes (2002), quando existem relações pobres no ambiente laboral e há pouca confiança, produzem-se, frequentemente, comunicações insuficientes que originam tensões psicológicas e sentimentos de insatisfação no trabalho.

Relativo às correlações entre os fatores de stress, percebe-se que elas possuem valores entre 0,407 e 0,675 , consideradas moderadas. A correlação mais alta $(0,675)$ é encontrada entre os fatores Stress1 (Autonomia/Controle) e Stress2 (Papéis e ambiente de trabalho), e expõe que há relação entre o fato de os indivíduos possuírem autonomia e controle sobre as atividades que exercem, desde que tenham o conhecimento adequado dessas atividades e não recebam ordens contraditórias por parte do superior. Caso contrário, o funcionário passa a desenvolver sintomas de mau humor e nervosismo. Nesse mesmo sentido, Corrêa e Menezes (2002) afirmam que o stress, no ambiente de trabalho, pode ser desencadeado quando não se dispõe de informação adequada, responsabilidade ou falta de clareza sobre os objetivos associados à função exercida. Outra consideração relevante é que, ao se analisar os valores das correlações entre os fatores de stress, observa-se que o fato de os coeficientes não assumirem valores altos indica que nenhuma das dimensões sozinha é suficiente para entender o stress, mostrando a importância de se considerar os diferentes fatores. Salienta-se, assim, que o stress é um construto multidimensional e, apresentá-lo em um único fator, como no trabalho de Paschoal e Tamayo (2004), pode não ser suficiente para abranger todas as suas dimensões.

Esse mesmo fato ocorre entre as correlações dos fatores de saúde organizacional. No modelo original, de Gomide Jr. et al. (1999 apud GOMIDE Jr.; FERNANDES, 2008), as variáveis são dispostas em apenas dois fatores, o que não se confirma neste trabalho. Como se pode perceber, os quatro 
fatores encontrados para descrever o construto de percepção de saúde organizacional se correlacionam de maneira satisfatória, variando de 0,476 a 0,634. Novamente, destaca-se que os resultados sugerem a necessidade de maiores investigações quanto à utilização de apenas dois fatores para medir a percepção de saúde organizacional, uma vez que, em amostras distintas, surgem números diferentes de fatores, sendo todos confiáveis. Ainda, salienta-se que a correlação entre os fatores Saúde1 (Integração de pessoas e equipes) e Saúde2 (Inovação e eficiência) foi a que apresentou valor mais elevado $(0,634)$, indicando que possui relação o fato de os funcionários da empresa trabalharem de forma cooperativa e buscarem por inovações e eficiência nas tarefas que desempenham, considerando o trabalho como algo prazeroso e importante.

\subsection{Análise de Regressão para os Fatores de Saúde Organizacional como Preditores do Stress Ocupacional}

Para investigar a influência da percepção de saúde organizacional sobre o stress no trabalho dos funcionários de restaurantes da cidade de Santa Maria - RS, realizou-se uma análise de regressão múltipla. Foram elaborados seis modelos de regressão, através do método stepwise, cada um deles tendo como variáveis independentes os fatores de saúde organizacional e a natureza do restaurante (público/privado) em que o funcionário trabalha; e como variável dependente cada um dos fatores de stress ocupacional e o fator geral de stress (Quadro 3). O método stepwise, a cada passo, insere a variável que possui a menor probabilidade $F e$ avalia as novas probabilidades $F$ das variáveis pertencentes ao modelo, retirando as variáveis cuja probabilidade torna-se grande. A significância dos modelos de regressão estimados foi testada pela distribuição $\boldsymbol{t}$ de Student, enquanto que o teste F-ANOVA foi utilizado para verificar o efeito ou influência que o conjunto das variáveis independentes exerce sobre a variável dependente (CORRAR; PAULO; DIAS FILHO, 2007).

Para medir a qualidade de ajustamento de uma linha de regressão, utilizou-se o coeficiente de determinação múltiplo ajustado $\left(\mathrm{R}^{2}\right)$, que conforme Levine, Berenson e Stephan (2000), representa a proporção da variação em Y que é explicada pelo conjunto de variáveis explicativas selecionadas, ou seja, é uma medida de ajuste da reta de regressão. 


\begin{tabular}{|c|c|c|c|c|c|c|c|c|}
\hline \multirow[t]{2}{*}{ Modelo } & \multirow{2}{*}{$\begin{array}{l}\text { Variável } \\
\text { Independente }\end{array}$} & \multicolumn{2}{|c|}{ Coeficiente } & \multicolumn{2}{|c|}{ Constante } & \multirow[b]{2}{*}{$R^{2}$} & \multicolumn{2}{|c|}{$\boldsymbol{F}$} \\
\hline & & Valor & Sig. & Valor & Sig. & & Valor & Sig \\
\hline Stress1 & Saúde2 & $-0,495$ & 0,000 & 4,426 & 0,000 & 0,239 & 44,362 & 0,000 \\
\hline \multirow{2}{*}{ Stress2 } & Saúde1 & $-0,389$ & 0,000 & \multirow{2}{*}{4,012} & 0,000 & \multirow{2}{*}{0,147} & \multirow{2}{*}{12,856} & \multirow{2}{*}{0,000} \\
\hline & Dummy & $-0,160$ & 0,000 & & 0,000 & & & \\
\hline Stress3 & Saúde4 & $-0,344$ & 0,000 & 4,532 & 0,000 & 0,112 & 18,335 & 0,000 \\
\hline \multirow{2}{*}{ Stress4 } & Dummy &,- 292 & 0,000 & \multirow{2}{*}{4,413} & 0,000 & \multirow{2}{*}{0,163} & \multirow{2}{*}{14,425} & \multirow{2}{*}{0,000} \\
\hline & Saúde1 &,- 345 & 0,000 & & 0,000 & & & \\
\hline Stress5 & Saúde4 &,- 363 & 0,000 & 4,555 & 0,000 & 0,125 & 20,763 & 0,000 \\
\hline \multirow{2}{*}{ Stress Geral } & Saúde4 &,- 301 & 0,000 & \multirow{2}{*}{4,456} & 0,000 & \multirow{2}{*}{0,206} & \multirow{2}{*}{18,918} & \multirow{2}{*}{0,000} \\
\hline & Saúde2 &,- 225 & 0,000 & & 0,000 & & & \\
\hline
\end{tabular}

Quadro 3: Coeficientes dos modelos de regressão

Fonte: Elaborado pelo autor (2009)

Observa-se que, para todos os modelos, a constante é significativa e assume um valor alto, uma vez que as questões foram desenvolvidas numa escala de 1 a 5 . Todos os valores do teste $\mathrm{F}$ foram significativos, indicando que, pelo menos, uma das variáveis independentes exerce influência sobre a variável dependente.

Para os modelos Stress2 e Stress4, as variáveis influenciadoras foram as mesmas, Saúde1 e Dummy. A variável Saúde1 exerce influência negativa, indicando que, quanto maior a concordância com os aspectos de integração de pessoas e equipes, representados por esse fator, menor o nível de stress ocupacional, relativo aos papéis, e o ambiente de trabalho e do Stress correspondente às "relações interpessoais". Esses resultados corroboram os pressupostos teóricos de que níveis baixos de saúde implicam alto grau de stress. Ainda, quanto aos fatores de stress, destaca-se que a natureza dos restaurantes (público ou privado) os influencia, sendo que os restaurantes privados apresentam menor nível de stress.

Nos modelos Stress3 e Stress5 também se percebe a influência da mesma variável: Saúde4. Esse resultado indica que os fatores de stress, "relacionamento com o chefe" e "crescimento e valorização", são influenciados, de maneira negativa, pelo fator de saúde, Organização saudável. No que tange aos modelos Stress1 (relativo ao fator autonomia e controle) e stress geral, o qual corresponde à média de todos os fatores de 
stress, nota-se, em ambos, a influência do fator "inovação e eficiência", de saúde organizacional. Ainda, no modelo referente ao stress geral, nota-se influência negativa do fator "organização saudável".

Para todos os modelos, os valores de $\mathrm{R}^{2}$ foram baixos, indicando que os fatores de stress ocupacional não são sufucientes para explicar a saúde organizacional. O Stress1, com maior $\mathrm{R}^{2}$ ajustado, mostra que apenas $24 \%$ do stress ocupacional pode ser explicado pela inovação e eficiência de saúde organizacional.

\begin{tabular}{|c|c|c|c|c|c|c|}
\hline Modelo & $\begin{array}{l}\text { Variável } \\
\text { Independente }\end{array}$ & Tol. & $\begin{array}{l}\text { Índice de } \\
\text { Condição }\end{array}$ & sig. KS & $\begin{array}{l}\text { Durbin } \\
\text { Watson }\end{array}$ & $\begin{array}{l}\text { sig. Pesaran- } \\
\text { Pesarán }\end{array}$ \\
\hline Stress1 & Saúde2 & & 7,989 & 0,531 & 1,512 & 0,581 \\
\hline \multirow{2}{*}{ Stress2 } & Saúde1 & \multirow{2}{*}{0,979} & 2,371 & \multirow{2}{*}{0,349} & \multirow{2}{*}{1,264} & \multirow{2}{*}{0,252} \\
\hline & Dummy & & 8,529 & & & \\
\hline Stress3 & Saúde4 & & 7,656 & 0,246 & 1,627 & 0,012 \\
\hline \multirow{2}{*}{ Stress4 } & Dummy & \multirow{2}{*}{0,979} & 2,371 & \multirow{2}{*}{0,261} & \multirow{2}{*}{1,638} & \multirow{2}{*}{0,761} \\
\hline & Saúde1 & & 8,529 & & & \\
\hline Stress 5 & Saúde4 & & 7,656 & 0,628 & 1,635 & 0,415 \\
\hline \multirow{2}{*}{ Stress Geral } & Saúde4 & \multirow{2}{*}{0,678} & 9,277 & \multirow{2}{*}{0,936} & \multirow{2}{*}{1,347} & \multirow{2}{*}{0,711} \\
\hline & Saúde2 & & 10,416 & & & \\
\hline
\end{tabular}

Quadro 3: Coeficientes dos modelos de regressão

Fonte: Elaborado pelo autor (2009)

Nota-se, através do Quadro 4, que todos os modelos atendem aos pressupostos de normalidade, pois os testes K-S apresentados não são significativos a 0,05 , aceitando a hipótese nula. $\mathrm{O}$ mesmo ocorre para a multicolinearidade, visualizada através da Tolerância, que, neste caso, apresentou valores satisfatórios, e do Índice de Condição, no qual os resultados foram menores do que 15. Ressalta-se que, para alguns modelos, o valor da tolerância não é apresentado, isso deriva do fato de os modelos apresentarem somente uma variável independente, o que impossibilita que ocorram problemas de multicolinearidade.

Porém, alguns modelos apresentaram problemas de homocedasticidade (Stress3) e autocorrelação (Stress1, Stress2 e Stress geral). A fim de tentar resolver esses problemas, as variáveis foram transformadas e os modelos estimados novamente. Adotou-se a transformação logaritmo natural. Apenas 
para o modelo Stress1 obteve-se resultados melhores no teste Durbin Watson $(1,67)$, aceitando, assim, a hipótese nula de não existência de autocorrelação nos resíduos.

Frente à análise dos modelos de regressão, gerados na primeira e na segunda etapa, pode-se considerar que o modelo Stress3 não apresentou pressupostos válidos, dessa forma, esse modelo foi desconsiderado. Os demais modelos, apresentaram pressupostos satisfatórios e podem ser utilizados para relacionar o Stress ocupacional e a saúde organizacional, ainda que em pequena proporção, visto os baixos valores de $\mathrm{R}^{2}$. Sobre o fator Stress geral, deve-se acrescentar que o teste Durbin Watson $(1,35)$ apresentou valor pouco abaixo do esperado, indicando a presença de autocorrelação entre os resíduos do modelo de regressão.

\section{Considerações Finais}

As novas práticas organizacionais, oriundas da reestruturação pela qual o mundo corporativo tem passado, sobretudo a partir de 1980, a fim de criar organizações mais flexíveis e adaptáveis, estão impactando diretamente na vida dos trabalhadores. Segundo Cooper (apud ROSSI; PERREWÉ; SAUTER, 2007) muitas organizações estão menores, com menos pessoas fazendo mais e sentindo-se menos seguras. Nota-se, assim, o surgimento do "supertrabalhador", que deve desenvolver as competências necessárias à sua função, tolerar ambiguidades e insegurança. Ou então, a fim de minimizar custos e dinamizar processos, está havendo um crescente número de funcionários temporários e de serviço autônomo nas empresas. Frente a esse cenário de transformações, o debate acerca da relação entre a saúde organizacional e o stress ocupacional exibe o necessário, visto que os colaboradores são uma fonte de eficiência para a organização.

A análise dos resultados mostrou diferenças entre públicos e privados, como o fato de os funcionários dos restaurantes públicos possuírem maior escolaridade, idade e tempo de serviço do que os funcionários dos restaurantes privados. Uma explicação plausível para esse achado refere-se à contratação de pessoas por meio de concursos, por parte dos restaurantes públicos. Ainda, observou-se que os funcionários dos restaurantes privados possuem uma média menor de tempo de serviço, o que pode estar relacionado com a duração indefinida da jornada de trabalho. 
Para o stress no trabalho foram obtidos cinco fatores que respondem a $64,95 \%$ da variância total acumulada e possuem boa confiabilidade, testada através do coeficiente de Alfa de Crombach. Para tais fatores, constatou-se que apenas o quarto fator, "Relações Interpessoais", apresenta diferença de médias significativa, demonstrando que a falta de comunicação, o tempo insuficiente para terminar o trabalho e a discriminação no ambiente laboral estão gerando mais stress ocupacional nos funcionários dos restaurantes públicos.

Para a saúde organizacional, a variância total explicada, para os seis fatores inicialmente formados, respondeu a 62,42\%. Porém, após a verificação da confiabilidade, dois fatores foram eliminados, sendo o modelo final constituído por quatro fatores. No que tange aos fatores de saúde organizacional, não foram encontradas diferenças de médias significativas para os restaurantes públicos e privados.

Finalmente, definiu-se seis modelos de regressão que têm como variável dependente os fatores de stress no trabalho e como variáveis independentes os fatores de saúde organizacional e os grupos de restaurantes. Observou-se que todos os coeficientes foram negativos, significando que há uma relação inversa entre saúde organizacional e stress ocupacional. A variável "Dummy" (restaurantes públicos/privados) somente foi significativa nos modelos que tinham como variável dependente os fatores Stress2 e Stress4. Esses modelos exibiram, através do $\mathrm{R}^{2}$ ajustado, baixo poder de explicação, indicando que os fatores de stress ocupacional não são sufucientes para explicar a saúde organizacional, devendo-se investigar outros aspectos relativos ao ambiente laboral que interferem na percepção de stress no trabalho.

Estudos futuros devem ser realizados, a fim de verificar a adequação dos fatores de saúde organizacional e stress no trabalho, já que se encontrou resultados válidos, porém distintos dos existentes na literatura. Assim, reaplicações com amostras variadas poderão contribuir para que se possa chegar a um consenso relativo a esses dois instrumentos. Estudos que investigam o comportamento organizacional e aspectos de saúde e stress do trabalhador são de extrema importância, dado que podem auxiliar na melhoria da qualidade de vida no trabalho e da própria qualidade de vida do colaborador, o que é sinônimo de maior produtividade, competitividade e satisfação no trabalho. 


\section{Sick Company, Stressed Employee: analyzing the organizational health like influencing the work-related stress}

\section{Abstract}

This study investigated the perceived Organizational Health influence on workrelated stress at the restaurants employees in the Santa Maria-RS city. To that end, it was used a survey from employee of the three public and four private restaurants. There has been a factor analysis showed those five factors for work-related stress and four factors of organizational health. Through an examination of correlation showed the multidimensionality of these constructs. Given these results, to check the influence of the perception of organizational health on occupational stress, there was a regression analysis and found to be valid five models that serve the conditions necessary. However, these models have low power of explanation, indicating that the factors of occupational stress are not sufficient to explain the organizational health, should to investigate other aspects of the work environment that interfere in the perception of work-related stress.

Key-words: Work-related Stress. Organizational Health. Restaurant Employee.

\section{Referências}

AAKER, D. A.; KUMAR, V.; DAY, G. S. Pesquisa de marketing. São Paulo: Atlas, 2004.

AVRICHIR, I.; DEWES, F. Construção e validação de um instrumento de avaliação do desempenho docente. In: Encontro Anual da Associação Nacional de Programas de Pós-Graduação em Administração. Salvador, 2006. Anais do ENANPAD: Salvador, 2006. CD-ROM.

BAKER, M. J. Selecting a research methodology. The Marketing Review, Scotland, Westburn Publishers Ltd, v. 1, p. 373-397, 2001.

BATEMAN, T. S.; STRASSER, S. A cross-lagged regression test of the relationships between job tension and employee satisfaction. Journal of Applied Psychology, Washington, v. 68, n. 3, p. 439-445, 1983. 
BERNSTORFF, V. H. Relações entre satisfação, competência, saúde e absenteísmo no trabalho em uma grande instituição bancária pública. Tese de Doutorado em Sociologia, Universidade Federal de Brasília, Brasília, 2007.

BOM SUCESSO, E. P. de. Trabalho e qualidade de vida. Rio de Janeiro: Dunya, 1997.

BROWN, S. P. A meta-analysis and review of organizational research on job environment. Psychological Bulletin, Washington, v. 120, n. 2, p. 235-255, 1996.

CABRAL, J. C. Qualidade de vida e fontes de pressão no trabalho de profissionais de cozinha: um estudo em restaurantes de Belo Horizonte. 2009. 157 p. Dissertação (Mestrado em Administração) - Faculdade Novos Horizontes, Belo Horizonte, 2009.

CAMERON, K. S. Effectiveness as paradox: consensus and conflict in conceptions of organizational effectiveness. Management Science, Linthicum,v. 32, n. 5, p. 539-553, 1986.

COOPER, C. L.; CARTWRIGHT, S. Managing workplace stress. London: Sage, 1996. Disponível em: <http://books.google.com.br/books>. Acesso em: 16 nov. 2008.

CORRAR, L. J.; PAULO, E.; DIAS FILHO, J. M. Análise multivariada: para os cursos de administração, ciências contábeis e economia. São Paulo: Atlas, 2007.

CORREAA, S. A.; MENEZES, J. R. M. Estresse e trabalho. 2002. 60 p. Monografia de Especialização em Medicina do Trabalho, Faculdade Estácio de Sá, Campo Grande, 2002.

COX, T.; HOWARTH, S. Organizational health, culture and helping. Work \& Stress, Nottingham, v. 4, n. 2, p. 107-110, 1990.

DEJOY, D. M.; WILSON, M. G. Organizational health promotion: broadening the horizon of workplace health promotion. American Journal of Health Promotion, Georgia, v. 17, n. 5, p. 337-341, 2003.

FORDYCE, J. K.; WEIL, R. Managing with people: a managers handbook methods. Reading, MA: Addison Wesley, 1971. 
GOMIDE Jr., S.; FERNANDES, M. N. Saúde Organizacional. In: SIQUEIRA, M. M. M. et. al. Medidas do comportamento organizacional: ferramentas de diagnóstico e de gestão. Porto Alegre: Artmed, 2008.

GUJARATI, D. N. Econometria básica. 3. ed. São Paulo: Makron Books, 2000.

HAIR, F. et al. Fundamentos de métodos de pesquisa em administração. Porto Alegre: Bookman, 2005.

HARTER, J. K.; SCHMIDT, F. L.; KEYES, C. L. Well-being in the workplace and its relationship to business outcomes: a review of the gallup studies. In: KEYES, C. L. e; HAIDT, J. (Eds.). Flourishing: The positive person and the good life. American Psychological Association, Washington, p. 205-224, 2002.

HERNANDEZ, J. D. Impactos da percepção de saúde organizacional no bem-estar no trabalho. 2007. 84 p. Dissertação (Mestrado em Psicologia) -Universidade Federal de Uberlândia, Uberlândia, 2007.

JAFFE, D. T. The healthy company: research paradigms for personal and organizational health. In: SAUTER, S. L. MURPHY, L. R. (Eds.)

Organizational risk factors for job stress. Washington DC: APA, 1995.

JEX, S. M.; ELACQUA, T. C. Self-esteem as a moderator: a comparison of global and organization-based measures. Journal of Occupational and Organizational Psycholoby, Leicester, v. 72, p. 71-81, 1999.

KARASEK, R. A. Job demands, job decision latitude, and mental strain: Implications for job redesign. Administrative Science Quarterly, New York, v. 24, p. 285-308, Jun. 1979.

KEYES, C. L. Social well-being. Social Psychology Quarterly, Chicago, v. 61, n. 2, p. 121-140, 1998.

KEYES, C. L. M.; HYSOM, S. J.; LUPO, K. L. The positive organization: leadership legitimacy, employee well-being, and the bottom line. The Psychologist-Manager Journal, Philadelphia, v. 4, n. 2, p. 143-153, 2000.

LATIF, S. A. A análise fatorial auxiliando a resolução de um problema real de pesquisa de marketing. Caderno de Pesquisas em Administração, São Paulo, v. 0, n. 0, 1994. 
LEVI, L. Guidance on work related stress: spice of life, or kiss of death? Newsletter of the European Trade Union Technical Bureau for Health and Safety (TUTB), Luxembourg, n. 19-20, p. 12-17, 2000.

LEVINE, D. M.; BERENSON, M. L.; STEPHAN, D. Estatística: teoria e aplicações. Rio de Janeiro: LTC, 2000.

LIMONGI FRANÇA, A. C.; RODRIGUES, A. L. Stress e Trabalho: uma abordagem psicossomática. 4. ed. São Paulo: Atlas, 2005.

MALHOTRA, N. K. Pesquisa de marketing: uma orientação aplicada. 3. ed. Porto Alegre: Bookman, 2006.

MARTINEZ, M. C. Estudo dos fatores associados à capacidade para o trabalho em trabalhadores do Setor Elétrico. 2006. 176 p. Tese de Doutorado em Saúde Publica, Faculdade de Saúde Publica da Universidade de São Paulo, São Paulo, 2006.

MASLACH, C. Entendendo o Burnout. In: ROSSI, A. M.; PERREWÉ, P. L.; SAUTER, S. L. Stress e qualidade de vida no trabalho: perspectivas atuais da saúde ocupacional. São Paulo: Atlas, 2007.

McCANN, J. E. Organizational effectiveness: changing concepts for changing. Environments Human Resource Planning, Chicago, v. 27, p. 42-50, 2004.

McCDONALD, J. M.; SHAVER, A. V. An absenteeism central program. Journal of Nursing Administration, Washington, v. 11, n. 5, p. 13-18, 1981.

MUCHINSKY, P. M. Psychology applied to work. Belmont, California: Wadsworth/Thompson Learning, 2003.

O'DONELL, M. P. Health promotion in the workplace. Albany:

Thompson Learning, 2001. Disponível em: < http://books.google.com/books>. Acesso em: 14 nov. 2008.

PASCHOAL, T.; TAMAYO, A. Validação da escala de stress no trabalho. Estudos de Psicologia, Natal, v. 9, n. 1, p. 45-52, 2004.

PESTANA, M. H.; GAGEIRO, J. N. Análise de dados para ciências sociais: a complementaridade do SPSS. Lisboa: Silabo, 2003. 
QUICK, J. C. et al. Líderes saudáveis, organizações saudáveis: prevenção primária e efeitos positivos da competência emocional. In: ROSSI, A. M.; PERREWÉ, P. L.; SAUTER, S. L. Stress e qualidade de vida no trabalho: perspectivas atuais da saúde ocupacional. São Paulo: Atlas, 2007.

ROSSI, A. M.; PERREWÉ, P. L.; SAUTER, S. L. Stress e qualidade de vida no trabalho: perspectivas atuais da saúde ocupacional. São Paulo: Atlas, 2007.

ROSSI, A. M. Apresentação international stress management association (ISMA-BR). In: ROSSI, A. M.; PERREWÉ, P. L.; SAUTER, S. L. Stress e qualidade de vida no trabalho: perspectivas atuais da saúde ocupacional. São Paulo: Atlas, 2007.

SHOAF, C. et al. Improving performance and quality of working life: a model for organizational health assessment in emerging enterprises. Human Factors and Ergonomics in Manufacturing, Hoboken (New Jersey), v. 14, n. 1, p. 81-95, 2004.

TAMAYO, A. Impacto dos valores da organização sobre o estresse ocupacional. RAC-Eletrônica, Curitiba, v. 1, n. 2, art. 2, p. 20-33, 2007. Disponível em: <http://www.anpad.org.br/rac-e>. Acesso em: 12 nov. 2008.

TRAVERS, C.; COOPER, C. L. Teachers under pressure: stress in the teaching profession. USA: Routledge, 1996. Disponível em: <http://books.google.com.br/books>. Acesso em: 16 nov. 2008.

VILLALOBOS, J. O. Estrés y trabajo. Instituto Mexicano del Seguro Social. México, 1999. Disponível em: <http://www.geocities.com/Athens/lthaca/3894>. Acesso em: 13 out. 2008.

WILSON, M. G., et al. Work characteristics and employee health and wellbeing: test of a model of healthy work organization. Journal of Occupational and Organizational Psychology, Leicester, v. 77, p. 565-588, 2004. 